\title{
Instrumental delivery: a comparative study in a tertiary care hospital
}

\author{
Bhanu B. T., Anitha G. S.* \\ Department of Obstetrics and Gynecology, Bangalore Medical College and Research Institute, Karnataka, India
}

Received: 08 January 2018

Accepted: 03 February 2018

\section{*Correspondence:}

Dr. Anitha G. S.,

E-mail: aninaik85@gmail.com

Copyright: $\odot$ the author(s), publisher and licensee Medip Academy. This is an open-access article distributed under the terms of the Creative Commons Attribution Non-Commercial License, which permits unrestricted non-commercial use, distribution, and reproduction in any medium, provided the original work is properly cited.

\section{ABSTRACT}

Background: To compare maternal and neonatal outcomes of vacuum versus forceps application in assisted vaginal delivery.

Methods: Women in labor with vertex presentation were delivered by indicated/propylactic vacuum or forceps. A total of 500 cases were included in this retrospective study. Maternal and neonatal morbidity were compared in terms of perineal lacerations, episiotomy extension, post-partum hemorrhage, Apgar score, neonatal jaundice, perinatal mortality, NICU admissions etc. Chi square test was used to analyze the data.

Results: Maternal morbidity was significant in the forceps group. With regards to neonatal morbidity, in NICU admissions, statistically significant difference was noted.

Conclusions: Vacuum and forceps should remain appropriate tools in the modern obstetrics. However, ventouse may be chosen first (if there is no fetal distress) as it is significantly less likely to injure the mother and decrease NICU admissions.

Keywords: Instrumental deliveries, Forceps, Ventouse

\section{INTRODUCTION}

In certain conditions normal, for various reasons, assisted vaginal delivery is the method of choice. Vaginal delivery being assisted by instruments can either be of vacuum extraction or forceps, a choice based on obstetrician's competence and training. ${ }^{1}$ As the rate of cesarean deliveries increased over the past 2 decades, the rate of operative vaginal delivery decreased from $9 \%$ of all deliveries in 1992 to $3.3 \%$ in 2013 in United States. ${ }^{2}$ Hence there is a need to relook and encourage operative vaginal deliveries.

James Young Simson was the first to use traction to deliver a baby. It was later modified by Malmstrom in 1953. The obstetric forceps has its history from the time of Chamberlain family in the seventh century. Vacuum extraction has recently gained in popularity because of new designs of vacuum cups, thereby minimizing injury to infants. ${ }^{3}$ However, a meta-analysis of randomized trials comparing maternal and infant outcomes between vacuum extraction and forceps deliveries have found that vacuum extraction causes less maternal trauma. ${ }^{4}$

This study has been carried out in our tertiary center to evaluate the maternal and neonatal morbidity, failure and complications associated with these two methods and to decide which is safer and more effective.

\section{METHODS}

A retrospective study was carried out in our tertiary care institution over a period of 2 years from January 2015 to December 2016. 500 consecutive cases of forceps delivery or ventouse extraction were included in this study.

The various indications for instrumental delivery were fetal distress, non-progressive second stage of labor, to cut short second stage of labor, poor maternal efforts. 
Written and informed consent was taken. Cases were scrutinized for demographic data, gestational age, birth weight and indication for instrumental delivery. Exclusion criteria from both the groups were cases of multiple pregnancy, preterm ( $<34 \mathrm{wks}$ of gestation) and breech presentation. Institutional ethical committee approval was taken. The instruments used for vacuum extraction were silastic $40 \mathrm{~mm}$ and $60 \mathrm{~mm}$ cups. The negative pressure applied was up to $0.6 \mathrm{~kg} / \mathrm{cm}$.

The forceps used was Wrigley's outlet forceps. Neonatal outcomes of interest were birth weight, Apgar score, NICU admission, cephalhematoma and scalp injuries. Maternal outcomes of interest were genital tract injuries like vaginal wall tear, cervical tear, vulvo-vaginal hematoma and $3^{\text {rd }}$ and $4^{\text {th }}$ degree perineal tears and postpartum hemorrhage. Condition of mother and baby at the time of discharge was noted. Data was entered and analyzed using Microsoft Excel and the results were expressed as proportions. Chi square test and student $t$ test were applied to find out the significance of association and $p$ value and $p$ value $<0.05$ was considered as statistically significant.

\section{RESULTS}

Out of the 500 cases of instrumental deliveries, vacuum was more preferred than forceps in our institution accounting for $71 \%$ of instrumental deliveries (Table 1).

Table 1: Instrumental deliveries.

\begin{tabular}{|ll|}
\hline Instrument delivery & $\%$ \\
\hline Forceps delivery (\%) & $143(28.6)$ \\
\hline Vacuum extraction (\%) & $357(71.4)$ \\
\hline
\end{tabular}

Table 2: Characteristics of the study group.

\begin{tabular}{|lll|}
\hline $\begin{array}{l}\text { Maternal } \\
\text { characteristics }\end{array}$ & Forceps (143) & $\begin{array}{l}\text { Vacuum } \\
(357)\end{array}$ \\
\hline Mean age in years & $23.1(3.2)$ & $22.9(3.3)$ \\
\hline $\begin{array}{l}\text { Mean gestational age } \\
\text { in weeks }\end{array}$ & 38.2 & 38.6 \\
\hline Nulliparity (\%) & $116(81 \%)$ & $232(65 \%)$ \\
\hline Primiparity (\%) & $23(16.2 \%)$ & $99(27.7 \%)$ \\
\hline Multiparity (\%) & $4(2.8 \%)$ & $26(7.3 \%)$ \\
\hline
\end{tabular}

Maternal age and gestational age in both the groups were comparable.

The majority of the instrumental deliveries in both the groups were in nulliparous women. (Table 2).

In our study $12 \%$ of study group was constituted by teenage pregnancies, 16 women of 18 years and 44 women of 19 years.

Prolonged second stage of labor was the most common indication for forceps deliveries and meconium stained amniotic fluid was the commonest indication among vacuum deliveries. To cut short the second stage of labor (indication 5,6,7and 8) forceps was used in 8.4\% and vacuum was used in $23 \%$ of the total cases. Other indications were failure of maternal powers and fetal distress.

Table 3: Indications for instrumental delivery.

\begin{tabular}{|lll|}
\hline $\begin{array}{l}\text { Indication for } \\
\text { instrumental delivery }\end{array}$ & $\begin{array}{l}\text { Forceps } \\
\text { Total-143 }\end{array}$ & $\begin{array}{l}\text { Vacuum } \\
\text { Total-357 }\end{array}$ \\
\hline Prolonged second stage & $34(23.8 \%)$ & $62(17.4 \%)$ \\
\hline $\begin{array}{l}\text { Failure of maternal } \\
\text { powers }\end{array}$ & $24(16.8 \%)$ & $67(18.8 \%)$ \\
\hline $\begin{array}{l}\text { Fetal distress } \\
\text { Meconium stained } \\
\text { amniotic fluid }\end{array}$ & $24(16.8 \%)$ & $31(8.7 \%)$ \\
\hline Eclampsia/preeclampsia & $21(14.7 \%)$ & $65(18.2 \%)$ \\
\hline $\begin{array}{l}\text { Vaginal birth after } \\
\text { caesarean delivery }\end{array}$ & $18(12.6 \%)$ & $24(6.7 \%)$ \\
\hline Anaemia & $1(0.7 \%)$ & $16(4.5 \%)$ \\
\hline Cardiac disease & $2(1.4 \%)$ & $10(2.8 \%)$ \\
\hline
\end{tabular}

Table 4: Birth weight.

\begin{tabular}{|lll|}
\hline Characteristics & $\begin{array}{l}\text { Forceps } \\
\text { mean (SD) }\end{array}$ & $\begin{array}{l}\text { Vacuum } \\
\text { mean (SD) }\end{array}$ \\
\hline Birth weight $(\mathrm{kg})$ & $2.94(0.389)$ & $2.85(0.432)$ \\
\hline
\end{tabular}

Mean birth weight was $2.94 \mathrm{~kg}$ in forceps group and 2.85 $\mathrm{kg}$ in vacuum group and the difference was statistically significant. ( $\mathrm{P}$ value 0.027 by students independent $\mathrm{t}$ test). Mean birth weight in our study was $2.88 \mathrm{~kg}$.

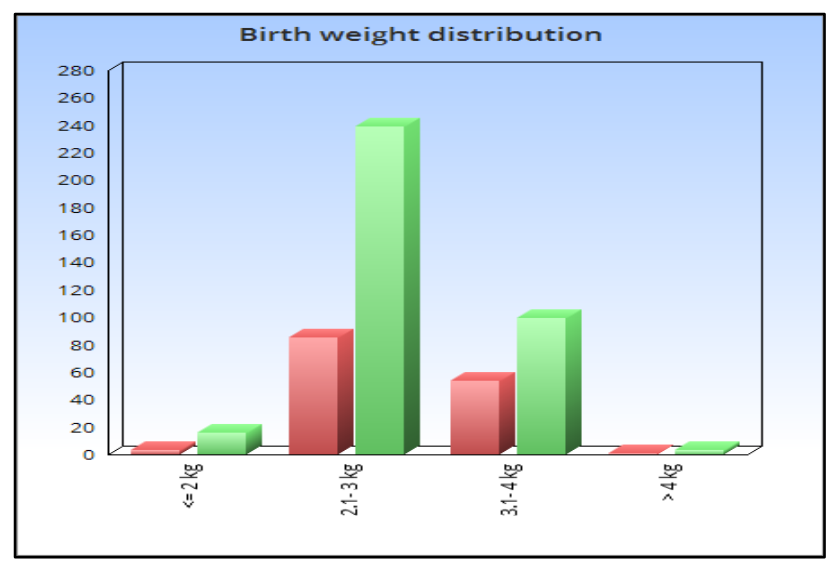

Pink- forceps, green- vacuum

\section{Figure 1: Birthweight distribution.}

Majority of the babies were in the birth weight group of 2.1 to $3 \mathrm{~kg}$. $38.4 \%$ of the babies in the forceps group were $>3 \mathrm{~kg}$ and it was $28.5 \%$ in vacuum group.

Table 5 shows that maternal morbidity such as cervical tear, paraurethral tears, vaginal tears and perineal tears were observed more frequently after forceps application. The difference in the incidence of significant maternal trauma was statistically significant. 
Table 5: Maternal morbidity.

\begin{tabular}{|lll|}
\hline Maternal morbidity & $\begin{array}{l}\text { Forceps } \\
(\%)\end{array}$ & $\begin{array}{l}\text { Vacuum } \\
(\%)\end{array}$ \\
\hline Episiotomy extension & $42(29.3)$ & $86(24)$ \\
\hline Vaginal wall tear & $53(37)$ & $26(7.2)$ \\
\hline Paraurethral tear & $15(10.4)$ & $23(6.4)$ \\
\hline $3^{\text {rd }}$ degree perineal tear & $10(6.9)$ & $6(1.7)$ \\
\hline Complete perinear tear & $6(4.2)$ & $1(0.2)$ \\
\hline Cervical tear & $14(9.7)$ & $8(2.2)$ \\
\hline Haematoma & $2(1.3)$ & $4(1.1)$ \\
\hline $\begin{array}{l}* \text { Significant maternal } \\
\text { trauma- 4,5,6,7 }\end{array}$ & $32(22 \%)$ & $19(5 \%)$ \\
\hline
\end{tabular}

*Statistically significant because $\mathrm{P}$ value $<0.05$

Table 6 shows the neonatal morbidity in the 2 groups. There was no significant difference between the 2 groups in neonatal morbidity except in NICU admissions.

Table 6: Neonatal morbidity.

\begin{tabular}{|lll|}
\hline Neonatal morbidity & Forceps & Vacuum \\
\hline Neonatal jaundice & 29 & 50 \\
\hline Cephalhaematoma & 2 & 4 \\
\hline Convulsions & 7 & 9 \\
\hline Brachial plexus injury & 1 & 1 \\
\hline Perinatal mortality & 7 & 7 \\
\hline NICU admissions* & 51 & 88 \\
* NICU admissions were higher in forceps group with statistical \\
significance since P value is $<0.05$.
\end{tabular}

\section{DISCUSSION}

Although deliveries by vacuum extraction and forceps are certainly not a substitute for caesarean delivery, they are safe obstetric practices with many benefits when protocols are followed and can be accomplished more quickly than cesarean delivery.

The mean age of women in our study was 23 years. The two groups did not vary significantly with respect to age and parity.

Mean birth weight in present study was $2.88 \mathrm{~kg}$. Majority of the babies were in the birthweight group of $2.1-3 \mathrm{kgs}$. According to a study the use of instruments is more frequent in infants with higher birth weight and gestational age. ${ }^{5}$ But the babies with higher birth weights $(>4 \mathrm{~kg}$ ) were only 4 in this study as they were preferentially taken for elective cesarean.

Table 6 shows that maternal morbidity was significantly less in ventouse group as compared to forceps group which is in accordance with the results of Cochrane Database. ${ }^{6}$ In present study maternal morbidity such as cervical tear, paraurethral tears, vaginal tears and perineal tears were observed more frequently after forceps application.
In a review of randomized trials comparing forceps deliveries with vacuum deliveries authors found that, forceps were more likely to be associated with third and fourth degree perineal tears (RR, 1.89; 95\% CI, 1.512.37) with no difference in the occurrence of cephalhematoma (RR, 0.64; 95\% CI, 0.37-1.11). ${ }^{7}$

In this study there was no statistically significant difference in neonatal morbidity except in NICU admissions. Neonatal morbidity differs substantially among various published reports. ${ }^{8-11}$ In a review of 13 randomized trials comparing forceps with vacuum extraction no significant differences were found in umbilical $\mathrm{pH}$, severe morbidity or neonatal death. ${ }^{7}$

Long term maternal and neonatal outcomes were also not studied in the study.

\section{CONCLUSION}

Our study analyzed maternal and fetal outcomes in instrumental deliveries. Our study opines that ventouse application is associated with significantly less maternal trauma than with forceps. There seems to be no difference in neonatal outcome. The major factor which determines the safety of the instrument is the operator rather than the instrument. Skill of the operator with an appropriate level of expertise and good judgment ensures better outcomes. Encouraging operative vaginal deliveries may help to reduce the unwarranted and raised caesarean section rates. The art of instrumental delivery using either vacuum or forceps should be taught to the residents. Also, those who have learnt its usage, but are not using it any longer, should undergo training workshops to update themselves so as to reach the WHO recommendation of a $10-15 \%$ caesarean section rate set to achieve optimal maternal and perinatal safety.

\section{Funding: No funding sources \\ Conflict of interest: None declared}

Ethical approval: The study was approved by the Institutional Ethics Committee

\section{REFERENCES}

1. Anonymous. Vacuum versus forceps. (Editorial). Lancet. 1984;1:144.

2. Martin JA, Hamilton BE, Osterman MJ, Curtin SC, Matthews TJ. Births: final data for 2013. Natl Vital Stat Rep. 2015;64: 1-65.

3. Johanson RB, Rice C, Doyle M, Arthur J, Anyanwu $\mathrm{L}$, Ibrahim $\mathrm{J}$, et al. A randomised prospective study comparing the new vacuum extractor policy with forceps delivery. Intern $\mathbf{J}$ Obstet Gynecol. 1993;100(6):524-30.

4. Caughey AB, Sandberg PL, Zlatnik MG, Thiet MP, Parer JT, Laros RK. Forceps compared with vacuum: rates of neonatal and maternal morbidity. Obstet Gynecol. 2006;107(3):740. 
5. Wu Wen S, Shiliang L, Kramer SM. Comparison of maternal and infant outcomes between vacuum extraction and forceps deliveries. Am J Epidemiol. 2001;153:103-7.

6. Johanson RB, Menon BK. Vacuum extraction versus forceps for assisted vaginal delivery. Cochrane Database Syst Rev. 2000;2:CD000224.

7. O'Mahony F, Hofmeyr GJ, Menon V. Choice of instruments for assisted vaginal delivery. Cochrane Database of Systematic Reviews. 2010:11. Art No: CD005455.DOI10.1002/14651858.CD005455.pub2. (meta-analysis)

8. Demissie K, Rhoads GG, Smulian JC, Balasubramanian BA, Gandhi K, Joseph KS, et al. Operative vaginal delivery and neonatal and infant adverse outcomes: population based retrospective analysis. BMJ. 2004;329(7456):24.

9. Gardella C, Taylor M, Benedetti T, Hitti J, Critchlow C. The effect of sequential use of vacuum and forceps for assisted vaginal delivery on neonatal and maternal outcomes. Am J Obstet Gynecol. 2001;185(4):896-902.

10. Lamba A, Kaur R, Muzafar Z. An observational study to evaluate the maternal and neonatal outcome of forceps delivery in a tertiary care government hospital of a cosmopolitan city of India. Res Obstet Gynecol. 2016;20(17):24.

11. Prameela RC, Prajwal S. Assisted vaginal delivery, Forceps, Ventouse. Outcome of instrumental vaginal deliveries in referred cases. JEMDS. 2015;4(19):3275-80.

Cite this article as: Bhanu BT, Anitha GS. Instrumental delivery: a comparative study in a tertiary care hospital. Int J Reprod Contracept Obstet Gynecol 2018;7:1079-82. 